\title{
Parkinson's disease dementia and dementia with Lewy bodies - epidemiology, risk factors and biomarkers
}

\author{
Eirik Auning $^{1,2}$, Arvid Rongve ${ }^{3}$ and Dag Aarsland ${ }^{2,4,5}$ \\ 1) Department of Geriatric Psychiatry, Akershus University Hospital, Lørenskog, Norway \\ 2) University of Oslo, Ahus Campus, Oslo, Norway \\ 3) Department of Geriatric Psychiatry, Haugesund Hospital, Haugesund, Norway \\ 4) Alzheimer's Disease Research Centre, Department of Neurobiology, Care Sciences and Society, \\ Karolinska Institutet, Novum, 14186 Stockholm, Sweden \\ 5) Centre for Age-Related Diseases, Stavanger University Hospital, 4000 Stavanger, Norway \\ E-mail: eirik.auning@ahus.no
}

\begin{abstract}
Dementia with Lewy bodies (DLB) and Parkinson's disease dementia (PDD) are common and debilitating dementia syndromes accompanied by Parkinsonism and a range of other psychiatric, sleep and autonomic disturbances. Disease mechanisms are unknown, but aggregated Lewy bodies containing alpha-synuclein are believed to play a central role in the pathogenesis. Point-prevalence of dementia in Parkinson's disease (PD) is approximately $30 \%$, and the majority develop dementia as the disease progresses. Recent studies suggest that $25-30 \%$ of non-demented PD patients have mild cognitive impairment (MCI), and 15-20\% already have it at the time of the diagnosis. PD-MCI is a strong predictor of PDD. There are few welldesigned epidemiological studies of DLB, but available evidence suggests that $15-20 \%$ of the total dementia population have DLB. Predicting future cognitive impairment is a priority, but the pre-dementia stage of DLB is essentially unexplored. Promising biomarkers are being researched, but, given the complexity of this disease, a multimodal approach is more likely to permit diagnostic precision in the future.
\end{abstract}

\section{INTRODUCTION}

James Parkinson's "essay on the shaking palsy" written in 1817, was the first clinical description of a patient group characterized by motor symptoms such as slowing of movement, tremor and flexed posture (1). Almost a hundred years later Friedrich Lewy discovered that abnormal aggregates of intracytoplasmatic proteins could be found in the brainstem of Parkinson's disease (PD) patients, now known under the eponym of Lewy bodies. Lewy bodies in the substantia nigra are now regarded as the hallmark of idiopathic $\mathrm{PD}$, but the underlying mechanisms are still unknown. Although Friedrich Lewy described significant cognitive impairment in PD patients, he did not connect this important observation to protein aggregation and development of dementia, and for decades PD was still regarded as a disease with pure motor dysfunction. From 1960 and later more sensitive immunocytochemical methods could detect Lewy bodies also in cortical and limbic structures in patients with dementia both with and without typical motor symptoms. Similar histopathological changes were also seen in the peripheral nervous system raising awareness of a disease group with a diversity of symptoms affecting several transmitter systems (2,3). Together with the remarkable efficacy of dopaminergic drugs in the treatment of motor symptoms, these important findings initiated an increased interest in cognitive impairment and other non-motor features in PD and related disorders. The recent detection of alpha-synuclein as the main constituent of Lewy bodies was another breakthrough (4).
A new distinct dementia subtype emerged with alphasynuclein containing Lewy bodies as the defining hallmark. The clinical phenotype and histopathology were different from that of vascular dementia and Alzheimer disease, and thus the first clinical criteria for dementia with Lewy bodies (DLB) and clinical, diagnostic criteria for dementia associated with PD (PDD) were proposed in 1996 and 2007 respectively $(5,6)$. There has been much debate as to whether these two disorders are different, but the common view now is that the similarities dominate, and that the relative timing of dementia and motor symptoms is the major difference. Lewy body disease has thus been proposed as an umbrella term for PD, PDD and DLB (7).

In this review we will attempt to address the important feature of cognitive impairment in Lewy body disease. Despite similarities between DLB and PDD, we will describe the current known risk factors and epidemiology separately. We will review the current status of both established and potential future biomarkers, such as clinical features, genetics, cerebrospinal fluid (CSF) and imaging parameters.

\section{THE PREVALENCE AND INCIDENCE OF DLB}

DLB is defined by the presence of dementia together with two of three core symptoms: (1) Parkinsonism, (2) typically well-formed and persistent visual hallucinations and (3) fluctuating cognition and/or consciousness (5). According to the revised clinical diagnostic criteria from 2005, a probable DLB diagnosis can be made with only one core symptom together with one 
Table 1. Community-based studies reporting the frequency of dementia with Lewy bodies (DLB).

\begin{tabular}{lccccl}
\hline Reference & N & Criteria* $^{*}$ & Age & Frequency & Comment \\
\hline (MRC-CFAS, 2001)*** & 109 & $\mathrm{P}$ & $>70$ & $12 \%$ & MRC-CFAS study, UK \\
(Yamada, 2001) & 142 & 1 & $\geq 65$ & $0.1 \%$ & Rural town, Japan \\
(Miech, 2002) & 185 & 0 & $\geq 65$ & $3.2 \%$ & Cache County Study, US \\
(Herrera, 2002) & 118 & 1 & $\geq 65$ & $1.7 \%$ & Brazil \\
(Shaji, 2002) & 51 & 1 & $>60$ & $12 \%$ & Kerala, India \\
\hline (Stevens, 2002) & 107 & 1 & $\geq 65$ & $30.5 \%$ & Only patients with VH$^{1}$ included \\
(de Silva, 2003) & 28 & 1 & $\geq 65$ & $3.6 \%$ & Semi-urban population, India \\
(Harvey, 2003) & 227 & $\mathrm{CC}$ & $<65$ & $7 \%$ & Age below 65 years, UK \\
(Wakisaka, 2003) & $102 * * *$ & $\mathrm{P}$ & $>65$ & $41.4 \%$ & Community based pathology study, Japan \\
(Lopez, 2003) & 707 & 1 & $>65$ & $3.5 \%$ & US Cardiovascular Health Cognition Study \\
(Rahkonen, 2003) & 137 & 1 & $\geq 75$ & $21.9 \%$ & Persons aged 75 or older in Finland \\
(Sambrook, 2004) & 766 & 1 & $>60$ & $3 \%$ & Canadian Outcomes Study in Dementia \\
(Lam, 2008) & 2073 & 1 & $>70$ & $3.6 \% * *$ & Thematic Household Study, Hong Kong \\
(de Pedro-Cuesta, 2009) & 1194 & 0 & $>70$ & $0.8-2 \%$ & Reanalysis of Spanish community surveys \\
(Matsui, 2009) & 275 & $\mathrm{P}$ & $\geq 65$ & $10.6 \%$ & Pathologically verified diagnoses Japan \\
\hline
\end{tabular}

Notes: *Criteria $1=$ McKeith et al. $1996,0=$ no criteria, $C C=$ clinical criteria, $\mathrm{P}=$ pathological. **DLB+Parkinson's disease dementia (PDD) ***29 demented ****("Pathological correlates of late-onset dementia in a multicentre, community-based population in England and Wales. Neuropathology Group of the Medical Research Council Cognitive Function and Ageing Study (MRC CFAS)", 2001)

${ }^{1}$ Visual hallucinations

or more suggestive features like REM sleep Behavior Disorder (RBD), neuroleptic hypersensitivity or a pathological single photon emission computed tomography (SPECT) using an ioflupane ( $\left.{ }^{123} \mathrm{I}\right)$ biomarker (DaTSCAN) (8). A diagnosis of possible DLB can be made with only one core or suggestive feature. In addition, the consensus criteria list a number of supporting clinical features like frequent falls, psychotic and depressive symptoms and autonomic failure. The revised clinical criteria awaits further systematic validation, but the sensitivity and specificity has been found to increase if RBD is added as a core feature (sensitivity $90 \%$ ) and cognitive fluctuation excluded (specificity $85 \%$ ) in advanced disease (9).

Few community-based epidemiological studies have focused on DLB and few have applied the clinical diagnostic criteria (table 1). In a review of epidemiological studies Zaccai and her colleagues concluded that the prevalence of DLB ranges from 0 to $5 \%$ with regard to the general population and from 0 to $30.5 \%$ of all dementia cases. A large part of this variation is probably due to methodological differences (10). Symptoms such as fluctuation are hard to identify clinically if not specifically investigated, and instruments like the Mayo Fluctuations Scale and the Clinician Fluctuation Inventory are recommended as screening instruments for this purpose $(11,12)$. The same holds true regarding the RBD, and therefore, the Mayo Sleep Questionnaire is recommended to screen for sleep disorders in dementia in clinical settings (13).

Among the most systematic studies are the Islington study from Britain, the Kuopio study from Finland and a community-based survey from Japan. This population-based Hisayama Study found DLB in
$10.6 \%$ of neuropathologically confirmed dementia cases and pure DLB was confirmed neuropathologically in $4.4 \%$ (14). The British Islington Community Study of Dementia in North London included 107 patients with dementia. It found $9.7 \%$ with a clinical diagnosis of probable DLB, while $30.5 \%$ had combined possible or probable DLB (15). A health survey in the Kuopio area in Finland of people aged 75 years or older found the proportion of DLB to be $21.9 \%$ of all dementia cases (16). These three studies provide the best estimates of the prevalence of DLB in the general population and suggest that DLB accounts for $10-22 \%$ of dementia cases in the 65 years or older age group, indicating that about $1 \%$ of the population over 65 years may suffer from DLB. In the DemVest study in Western Norway we applied the revised consensus criteria on a referral cohort to old age psychiatry and geriatric medicine clinics, including all referrals with a first time diagnosis of mild dementia (defined as a Mini Mental State Examination (MMSE) score of 20 or more). In our study, $15.8 \%$ of persons with mild dementia were diagnosed with probable DLB and 20\% with possible and probable DLB combined with other symptoms (17). Only four incidence studies exist and report the incidence of DLB from 0.7 to 1.4 new cases for every 1,000 persons per year $(14,18-20)$ (table 2$)$.

\section{RISK FACTORS FOR DEVELOPING DLB}

Very few studies have explored the early, predementia stages of DLB, but evidence is emerging to suggest that several possible starting points and trajectories can lead to the pathological and clinical syndrome of DLB (Figure 1). 
Table 2. Studies reporting the incidence of dementia with Lewy bodies (DLB).

\begin{tabular}{|c|c|c|c|}
\hline Study & Age & $\mathbf{N}^{*}$ & DLB incidence \\
\hline (Matsui et al., 2009) Hisayama-study & $65+$ & $828 / 81$ & 1.4 per 1000 persons per year \\
\hline (de Lau et al., 2004) & $55+$ & $6839^{1}$ & $\begin{array}{l}0.7 \text { per } 1000 \text { persons per year } \\
(95 \% \text { CI } 0.4-1.0)\end{array}$ \\
\hline (Lopez-Pousa et al., 2004) & $75+$ & $1198 / 18$ & $\begin{array}{l}2 \% \text { of annual clinical dementia } \\
\text { incidence in a memory clinic. }\end{array}$ \\
\hline (Miech et al., 2002) & $65+$ & $185 / 6$ & $\begin{array}{l}0.1 \% \text { per year in general population. } \\
3.2 \% \text { per year of all new dementia }\end{array}$ \\
\hline
\end{tabular}

*Total population/DLB

1 DLB is not diagnosed by strict use of the diagnostic criteria, but the authors have made the assumption that subjects with Parkinsonism associated with dementia (numbering 26) all had DLB.

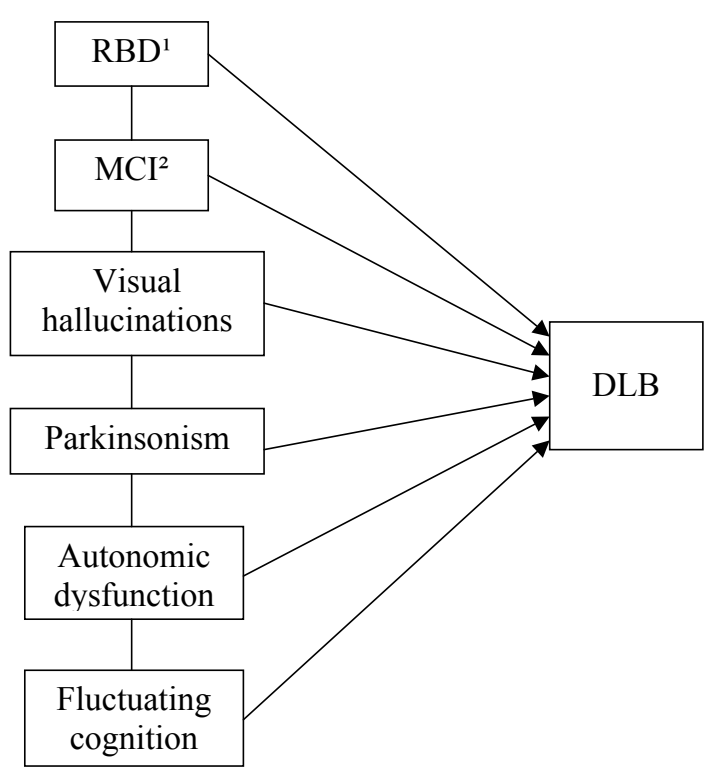

Figure 1. Potential presenting symptoms in DLB.

${ }^{1}$ REM sleep behavior disorder

${ }^{2}$ Mild cognitive impairment

\section{Genetic contributions}

Most DLB cases occur sporadically, although families have been described as having several members diagnosed with DLB with gene alterations in different locations, some of which overlap with PD and others with AD. Cousins of DLB patients have a 2.3 fold increased risk of developing DLB compared to members of the general population (21). Traditional genetic studies have identified multiplications $(22,23)$ and mutations in the gene encoding alpha-synuclein (2426) and beta-synuclein (27). Genetic mutations known to be risk factors of early onset familial Alzheimer's disease, like PSEN 1 and PSEN 2, have also been identified in DLB (28).

The APOE $\varepsilon 4$ allele is the strongest genetic risk factor for developing $\mathrm{AD}$, but in DLB there are conflicting results regarding APOE as a risk factor (29). Genome-wide association studies (GWAS) have not yet been presented for DLB but it is to be hoped that in the near future more of the underlying disease mechanism and risk factors will be revealed.

\section{Clinical features preceding $D L B$}

Mild cognitive impairment (MCI) has been shown to precede Alzheimer dementia (AD) with an annual conversion rate of about $10-15 \%$ (30), but the MCI stage of DLB is undefined and essentially unexplored. A clinicopathological study of eight MCI patients with subsequent autopsy-proven Lewy body disease shoved that RBD preceded MCI in six cases with a median of 12 years (31). The cognitive domains most frequently affected at the pre-dementia stage were attention, executive and visuospatial functioning. Memory was less frequently impaired. The same cognitive pattern was seen in another study with a similar design (32). Parkinsonism, visual hallucinations and delirium were shown to be early features compared to the MCI-stage of Alzheimer's disease, which is dominated by memory problems. In a retrospective study of 61 mildly demented DLB patients, carers reported visual hallucinations and memory impairment as the most frequent presenting symptoms, suggesting mixed and overlapping symptoms with AD-MCI (33). In another autopsyproven study, visual hallucinations were seen as the best positive predictor and the absence of visuospatial impairment the best negative predictor of a later diagnosis of DLB versus AD (34).

In the DemVest study we found higher frequencies of RBD and Excessive Daytime Sleepiness (EDS) in mild DLB compared to normal controls and mild AD patients. RBD started on average seven years (range 0.5-35 years) before dementia was diagnosed in 39 persons, indicating a strong association (unpublished data from the DemVest study). This long-duration preclinical phase was also demonstrated in another study (35). In a recent study RBD conferred a 2.2-fold increased risk of developing PD-MCI over four years (36).

Pure Autonomic Failure (PAF) is restricted clinically to the peripheral nervous system and includes orthostatic hypotension, constipation, olfactory dysfunction and urinary incontinence. PAF has been shown to be the initial presentation in both DLB and Parkinson's disease (37), and a positive DaTSCAN in PAF supports the hypothesis of a common etiology (38). 


\section{POTENTIAL BIOMARKERS IN DLB}

Due to the relatively low sensitivity of the consensus criteria for DLB, the need for reliable biomarkers is evident. A complicating factor is the heterogeneous brain pathology in DLB and the considerable overlap between neuropathological changes and clinical presentation in DLB and AD.

Among established biomarkers for AD are atrophy of the medial temporal lobe (hippocampus), a low concentration of beta-amyloid and a high concentration of total-tau and phospho-tau in the CSF $(39,40)$. These patterns can also be seen in DLB, but typically the hippocampus is less damaged and the CSF changes less clear in comparison with AD (41), and it cannot be used to separate DLB from AD on an individual level.

Reduced levels of alpha-synuclein in the CSF of DLB patients compared to that of those with AD have recently been demonstrated (42), but the studies are small and routine measurement of alpha-synuclein has proven technically difficult. At present, more confirmatory studies are needed in order to incorporate alphasynuclein as a good and valid biomarker for DLB.

Slowing of the EEG rhythm is a frequent finding in $\mathrm{AD}$ and other dementias, but several studies have shown a more pronounced slowing in DLB patients (43). These studies have, however, included few patients, and larger studies have shown conflicting results (43). In addition, none of the published studies report information about diagnostic sensitivity and specificity, and thus EEG findings cannot serve as a reliable biomarker for DLB.

Autonomic dysfunction involving the cardiovascular system is common in DLB and myocardial scintigraphy with ${ }^{123}$ I-metaiodobenzylguanidine (MIBG) enables the quantification of post-ganglionic cardiac sympathetic innervation. Several studies have demonstrated reduced cardiac uptake in DLB compared to AD patients (43), but larger multicentre studies are lacking and more conclusive evidence is pending.

Radiolabelled tracers used in SPECT can measure regional, cortical blood flow and show a typical pattern of reduced perfusion in temporoparietal areas in AD. In DLB a pattern of occipital and parietal hypoperfusion is more common, often referred to as the "horse-shoe sign". Similar findings have been found for fluorodeoxyglucose-positron emission tomography (FDG-PET) (44). Relatively few studies with small samples have assessed the precision of cerebral SPECT as a biomarker for DLB (43), and the available results are conflicting, indicating the need for multicentre studies for better diagnostic accuracy.

The most convincing evidence exists for ioflupane $\left({ }^{123} \mathrm{I}\right)$ SPECT (DaTSCAN), where radiolabelled ioflupane binds to the dopamine transporter in the striatum. In cases of reduction of dopaminergic neurons in the substantia nigra, the visualization of dopamine transporters is greatly reduced. These findings were first demonstrated in PD, but can now also be seen in pre- clinical cases of nigro-striatal degeneration including multiple system atrophy, progressive supranuclear palsy and DLB. This means that DLB patients without clinically detectable Parkinsonism can now be identified (45), whereas the scans of patients with AD are normal. In a large pivotal multicentre study, DaTSCAN demonstrated a sensitivity of $78 \%$ and a specificity of $90 \%$ in distinguishing probable DLB from AD (46).

Recent findings suggest that DaTSCAN could be of even greater clinical relevance in identifying patients with possible DLB. In a 12-month longitudinal study no patients with possible DLB and a normal scan at baseline had developed probable DLB at the follow-up examination. In contrast, 63\% (12 of 19) of subjects with an abnormal scan had probable DLB at followup, a significant difference (47). Thus, DaTSCAN can help to identify DLB at an early stage, before the full clinical syndrome has developed.

\section{THE PREVALENCE AND INCIDENCE OF PDD}

PDD is common, and the prevalence is estimated to be about $5 \%$ of all cases of dementia (17). Cognitive impairment in PD has recently been reviewed in detail (48).

Several cross-sectional epidemiological studies have reported that the proportion of PD patients who have dementia is approximately $30 \%(49,50)$. Cross-sectional studies, however, underestimate the proportion of people with dementia, since mortality in PD is influenced by dementia. Longitudinal studies have reported a six times higher risk of developing dementia in PD compared to people without PD of the same age. The incidence of dementia in cross-sectional PD cohorts is 100 per 100,000 patient-years. Consequently, a very high cumulative proportion of up to $80 \%$ with dementia has been reported among PD patients $(51,52)$. A lower incidence has been reported for the first years after diagnosis. In a longitudinal study based on an incidence PD-cohort, a dementia incidence of 30 per 100,000 person-years was reported (53) and slightly less than $50 \%$ of the cohort had developed dementia eight years after the diagnosis. The mean time-period to diagnosis with dementia was 6.2 years.

\section{Variations in the course of cognitive impairment}

There is a wide variation in the time from onset of PD to dementia. Whereas some patients develop dementia within a few years of the diagnosis, others do not show signs of dementia for more than 20 years (54). The mean rate of cognitive decline in $\mathrm{PD}$ is approximately 1 point per annum on the MMSE (55), but for unknown reasons there is large inter- and intra-individual variation in the rate of decline. As reported above, a slower rate of decline occurs in the early stages of the disease. Typically, in an individual PD patient, a period of no or very little decline is followed by an inflexion point after which a much more rapid decline occurs, with large inter-individual variation in the time-period to 
this inflexion point $(56,57)$. After the onset of PDD, the progression to the terminal stage of the illness is less variable, and there is an average of 3 years with increasing disability leading to death, whatever the age of onset (58). Identifying predictors of time to diagnosis of dementia and of the rate of cognitive decline is thus a key clinical and research priority.

\section{RISK FACTORS FOR EARLY COGNITIVE DECLINE IN PD}

A shorter time to cognitive impairment is associated with older age at diagnosis of PD, non-tremor dominant motor subtypes with significant postural instability and gait disturbances $(53,59)$. In addition, visual hallucinations, $\operatorname{RBD}(36,60)$ and olfactory dysfunction $(61)$ are associated with a shorter time to the development of dementia.

\section{Genetic contributions to cognitive impairment in PD}

Several studies have reported a familial association between dementia and PD, suggesting that genetic factors influence the emergence of cognitive impairment and dementia in PD (62). Despite the progress in identifying genes that cause or increase the risk of $\mathrm{PD}$, the specific genetic contribution to cognitive impairment in PD is not known.

The H1 and H1p haplotypes of the microtubuleassociated protein tau (MAPT) have been found to be significantly associated with dementia with significant odds ratios ranging from 1.35 to $3.7(63,64)$, although not consistently. Alpha-synuclein gene duplications may lead to cognitive impairments and dementia (65). PD patients with glucocerebrosidase (GBA) mutations have more frequent and severe cognitive impairments when compared to sporadic cases of PD (66), and glucocerebrosidase (GBA) mutation status may be an independent risk factor for cognitive impairment in patients with PD (67).

Other typical PD mutations such as LRRK2 and Parkin-mutations do not seem to be associated with the development of cognitive impairment (68). Mutations of the COMT gene are associated with dopaminerelated cognitive deficits, such as reduced attention, but do not seem be associated with increased risk of dementia (69). Finally, inconsistent results have been found regarding the associations between APOE genotype and butyrylcholinesterase- $\mathrm{K}$ genotypes and the risk of dementia (70-72).

\section{Mild cognitive impairment}

About $20-25 \%$ of PD patients without dementia have mild cognitive impairment (PD-MCI) (73). It is noteworthy that, even at the time of diagnosis, MCI is observed in $15-20 \%$ of people with PD, even in nontreated patients (74). Recently the Movement Disorders Society commissioned a task force (MDS-TF) which proposed the first clinical consensus criteria for MCI in PD (75). Importantly, the early cognitive changes in PD seem to predict subsequent development of de- mentia. The cognitive profile in PD is heterogeneous, and it has recently been demonstrated that impairments of visuospatial functions and memory occur in addition to the well-known attentional and executive deficits (76). Some evidence exists that semantic memory and visuospatial dysfunction, but not executive impairment, predict progression to dementia in PD patients (69). One interpretation of these findings is that frontal-type deficits are more related to dopaminergic lesions (causing more mild cognitive deficits), whereas the more posterior cognitive deficits may be associated with structural pathologies such as temporo-parietal Lewy bodies and plaque pathology (giving more rapid decline and dementia). Further studies are needed to test this hypothesis.

\section{BIOMARKERS PREDICTING COGNITIVE DECLINE IN PD}

Several different biomarkers have been associated with cognitive impairment in $\mathrm{PD}$, and recently several longitudinal studies have been reported (77-81). However, larger multicentre studies with robust and a priori defined cut-off points are necessary before these markers can be implemented in clinical practice.

\section{Structural imaging}

Most studies have used structural magnetic resonance imaging (MRI) and shown that atrophy of the parietaltemporal lobe, entorhinal cortex, hippocampus, prefrontal cortex and posterior cingulate cortex (82-86) are associated with PDD. Similar, but less marked, changes have also been identified in PD-MCI $(85,87)$. An AD-like pattern of atrophy (hippocampus, parietaltemporal cortex) was recently found to be related to cognitive performance in PD and it was suggested that these changes might be used to predict a global cognitive decline in non-demented patients over a 2-year follow-up period (88).

\section{EEG}

Quantitative electroencephalography (QEEG) studies suggest that low-frequency content is associated with cognitive impairment in PD, and that QEEG measures could also predict the risk of developing dementia in the future (77).

\section{PET}

Reduced glucose metabolism in both frontal and parietal cortex measured by FDG-PET has been found to be associated with cognitive decline in PD-MCI (89). More specifically, hypometabolism in the temporal cortex has been associated with verbal memory, in the frontal cortex with executive dysfunction and in the parietal cortices with visuospatial dysfunction (90). A recent longitudinal study suggested that early metabolic changes in visual association and posterior cingulate cortices could predict incident dementia in PD (81).

Perfusion SPECT

Cross-sectional studies using SPECT have reported hypoperfusion in lateral parietal and frontal cortex in 
PD patients without dementia, which correlated with cognitive impairment (91). Bilateral hypoperfusion in posterior parietal lobes and in the right occipital lobe were seen in PD-MCI, which differed from the pattern seen in non-PD-MCI (92). Perfusion has also been shown to aid in the prediction of cognitive decline in PD (80).

CSF

It has been reported that beta-amyloid (1-42) levels were lower and total-tau and p-tau were higher or normal in PDD patients when compared to PD patients without dementia and controls (93). Likewise, a prospective study indicated that lower baseline CSF betaamyloid (1-42), but not total-tau and p-tau (181p), was associated with more rapid cognitive decline (78). Detailed analyses of several splice variants of betaamyloid showed that early PD patients displayed significant reductions not only of CSF $A \beta 42$, but also $A \beta 40$ and $A \beta 38$. These reductions were associated with memory impairment, but not with executive-attentional or visuospatial dysfunction (94). These observations suggest that amyloid pathology contributes to cognitive impairment in PD.
Patients with PD and DLB have shown lower monomeric CSF alpha-synuclein levels than patients with $\mathrm{AD}$ and controls (95). Correlations between cognitive status and lower CSF alpha-synuclein have been reported in DLB (42), but at present not in PD. Alphasynuclein oligomers or phospho-alpha-synuclein (129p) in CSF has also been reported to be higher in patients with PD compared to patients with AD or controls (96).

\section{FINAL REMARKS - CONCLUSION}

Both DLB and PDD are common and highly debilitating syndromes with a variety of symptoms. The overall negative impact on the individual patient and the carer, as well as the health-related costs of Lewy body dementia are even higher than those of AD (97-99). Although the full clinical syndrome seen in DLB can occur also in PD, PD preceding dementia should be diagnosed as PDD rather than DLB.

Early disease detection is a priority in order to give patients and carers an explanation of the diversity of symptoms and to provide targeted medication and care.

\section{REFERENCES}

1. Parkinson J. An essay on the shaking palsy. Whittingham and Rowland, 1817.

2. Kosaka K, Oyanagi S, Matsushita M, Hori A. Presenile dementia with Alzheimer-, Pick- and Lewy-body changes. Acta Neuropathol 1976; 36 (3): 221-33.

3. Kosaka K, Yoshimura M, Ikeda K, Budka H. Diffuse type of Lewy body disease: progressive dementia with abundant cortical Lewy bodies and senile changes of varying degree - a new disease? Clin Neuropathol 1984; 3 (5): 185-92.

4. Spillantini MG, Crowther RA, Jakes R, Hasegawa M, Goedert M. alpha-Synuclein in filamentous inclusions of Lewy bodies from Parkinson's disease and dementia with lewy bodies. Proc Natl Acad Sci USA 1998; 95 (11): 6469-73.

5. McKeith IG, Galasko D, Kosaka K, Perry EK, Dickson DW, Hansen LA, et al. Consensus guidelines for the clinical and pathologic diagnosis of dementia with Lewy bodies (DLB): report of the consortium on DLB international workshop. Neurology 1996; 47 (5): 1113-24.

6. Dubois B, Burn D, Goetz C, Aarsland D, Brown RG, Broe GA, et al. Diagnostic procedures for Parkinson's disease dementia: recommendations from the movement disorder society task force. Mov Disord 2007; 22 (16): 2314-24.

7. Lippa CF, Duda JE, Grossman M, Hurtig HI, Aarsland D, Boeve BF, et al. DLB and PDD boundary issues: diagnosis, treatment, molecular pathology, and biomarkers. Neurology 2007; 68 (11): 812-9.

8. McKeith IG, Dickson DW, Lowe J, Emre M, O'Brien JT, Feldman H, et al. Diagnosis and management of dementia with Lewy bodies: third report of the DLB Consortium. Neurology 2005; 65 (12): 1863-72.

9. Ferman TJ, Boeve BF, Smith GE, Lin SC, Silber MH, Pedraza O, et al. Inclusion of RBD improves the diagnostic classification of dementia with Lewy bodies. Neurology 2011; 77 (9): 875-82.

10. Zaccai J, McCracken C, Brayne C. A systematic review of prevalence and incidence studies of dementia with Lewy bodies. Age Ageing 2005; 34 (6): 561-6.

11. Ferman TJ, Smith GE, Boeve BF, Ivnik RJ, Petersen RC, Knopman D, et al. DLB fluctuations: specific features that reliably differentiate DLB from AD and normal aging. Neurology 2004; 62 (2): 181-7.

12. Walker MP, Ayre GA, Cummings JL, Wesnes K, McKeith IG, O'Brien JT, et al. The Clinician Assessment of Fluctuation and the One Day Fluctuation Assessment Scale. Two methods to assess fluctuating confusion in dementia. Br J Psychiatry 2000; 177: 252-6.

13. Boeve BF, Molano JR, Ferman TJ, Smith GE, Lin SC, Bieniek K, et al. Validation of the Mayo Sleep Questionnaire to screen for REM sleep behavior disorder in an aging and dementia cohort. Sleep Medicine 2011; 12 (5): 445-53. 
14. Matsui Y, Tanizaki Y, Arima H, Yonemoto K, Doi Y, Ninomiya T, et al. Incidence and survival of dementia in a general population of Japanese elderly: the Hisayama study. J Neurol Neurosurg Psychiatry 2009; 80 (4): 366-70.

15. Stevens T, Livingston G, Kitchen G, Manela M, Walker Z, Katona C. Islington study of dementia subtypes in the community. Br J Psychiatry 2002; 180: 270-6.

16. Rahkonen T, Eloniemi-Sulkava U, Rissanen S, Vatanen A, Viramo P, Sulkava R. Dementia with Lewy bodies according to the consensus criteria in a general population aged 75 years or older. J Neurol Neurosurg Psychiatry 2003; 74 (6): 720-4.

17. Aarsland D, Rongve A, Nore SP, Skogseth R, Skulstad S, Ehrt U, et al. Frequency and case identification of dementia with Lewy bodies using the revised consensus criteria. Dement Geriatr Cogn Disord 2008; 26 (5): 445-52.

18. de Lau LM, Giesbergen PC, de Rijk MC, Hofman A, Koudstaal PJ, Breteler MM. Incidence of parkinsonism and Parkinson disease in a general population: the Rotterdam Study. Neurology 2004; 63 (7): 1240-4.

19. Lopez-Pousa S, Vilalta-Franch J, Llinas-Regla J, Garre-Olmo J, Roman GC. Incidence of dementia in a rural community in Spain: the Girona cohort study. Neuroepidemiology 2004; 23 (4): 170-7.

20. Miech RA, Breitner JC, Zandi PP, Khachaturian AS, Anthony JC, Mayer L. Incidence of AD may decline in the early 90s for men, later for women: The Cache County study. Neurology 2002; 58 (2): 209-18.

21. Nervi A, Reitz C, Tang MX, Santana V, Piriz A, Reyes D, et al. Familial aggregation of dementia with Lewy bodies. Arch Neurol 2011; 68 (1): 90-3.

22. Singleton AB, Farrer M, Johnson J, Singleton A, Hague S, Kachergus J, et al. alpha-Synuclein locus triplication causes Parkinson's disease. Science 2003; 302 (5646): 841.

23. Chartier-Harlin MC, Kachergus J, Roumier C, Mouroux V, Douay X, Lincoln S, et al. Alpha-synuclein locus duplication as a cause of familial Parkinson's disease. Lancet 2004; 364 (9440): 1167-9.

24. Polymeropoulos MH, Lavedan C, Leroy E, Ide SE, Dehejia A, Dutra A, et al. Mutation in the alpha-synuclein gene identified in families with Parkinson's disease. Science 1997; 276 (5321): 2045-7.

25. Zarranz JJ, Alegre J, Gomez-Esteban JC, Lezcano E, Ros R, Ampuero I, et al. The new mutation, E46K, of alpha-synuclein causes Parkinson and Lewy body dementia. Ann Neurol 2004; 55 (2): 164-73.

26. Yamaguchi K, Cochran EJ, Murrell JR, Polymeropoulos MH, Shannon KM, Crowther RA, et al. Abundant neuritic inclusions and microvacuolar changes in a case of diffuse Lewy body disease with the A53T mutation in the alpha-synuclein gene. Acta Neuropathol 2005; 110 (3): 298-305.

27. Ohtake H, Limprasert P, Fan Y, Onodera O, Kakita A, Takahashi H, et al. Beta-synuclein gene alterations in dementia with Lewy bodies. Neurology 2004; 63 (5): 805-11.

28. Meeus B, Verstraeten A, Crosiers D, Engelborghs S, Van den Broeck M, Mattheijssens M, et al. DLB and PDD: a role for mutations in dementia and Parkinson disease genes? Neurobiol Aging 2012; 33 (3): 629.

29. Singleton AB, Wharton A, O'Brien KK, Walker MP, McKeith IG, Ballard CG, et al. Clinical and neuropathological correlates of apolipoprotein E genotype in dementia with Lewy bodies. Dement Geriatr Cogn Disord 2002; 14 (4): 167-75.

30. Petersen RC, Roberts RO, Knopman DS, Boeve BF, Geda YE, Ivnik RJ, et al. Mild cognitive impairment: ten years late. Arch Neurol 2009; 66 (12): 1447-55.

31. Molano J, Boeve B, Ferman T, Smith G, Parisi J, Dickson D, et al. Mild cognitive impairment associated with limbic and neocortical Lewy body disease: a clinicopathological study. Brain 2010; 133 (Pt 2): 2-56.

32. Jicha GA, Schmitt FA, Abner E, Nelson PT, Cooper GE, Smith CD, et al. Prodromal clinical manifestations of neuropathologically confirmed Lewy body disease. Neurobiol Aging 2010; 31 (10): 1805-13.

33. Auning E, Rongve A, Fladby T, Booij J, Hortobagyi T, Siepel FJ, et al. Early and presenting symptoms of dementia with lewy bodies. Dement Geriatr Cogn Disord 2011; 32 (3): 202-8.

34. Tiraboschi P, Salmon DP, Hansen LA, Hofstetter RC, Thal LJ, Corey-Bloom J. What best differentiates Lewy body from Alzheimer's disease in early-stage dementia? Brain 2006; 129 (Pt 3): 3-35.

35. Claassen DO, Josephs KA, Ahlskog JE, Silber MH, Tippmann-Peikert M, Boeve BF. REM sleep behavior disorder preceding other aspects of synucleinopathies by up to half a century. Neurology 2010; 75 (6): 494-9.

36. Boot BP, Boeve BF, Roberts RO, Ferman TJ, Geda YE, Pankratz VS, et al. Probable rapid eye movement sleep behavior disorder increases risk for mild cognitive impairment and Parkinson disease: a populationbased study. Ann Neurol 2012; 71 (1): 49-56.

37. Kaufmann H, Nahm K, Purohit D, Wolfe D. Autonomic failure as the initial presentation of Parkinson disease and dementia with Lewy bodies. Neurology 2004; 63 (6): 1093-5.

38. Tolosa E, Borght TV, Moreno E, DaTSCAN Clinically Uncertain Parkinsonian Syndromes Study Group. Accuracy of DaTSCAN (123I-Ioflupane) SPECT in diagnosis of patients with clinically uncertain parkinsonism: 2-year follow-up of an open-label study. Mov Disord 2007; 22 (16): 2346-51.

39. Bloudek LM, Spackman DE, Blankenburg M, Sullivan SD. Review and meta-analysis of biomarkers and diagnostic imaging in Alzheimer's disease. J Alzheimer's Dis 2011; 26 (4): 627-45. 
40. Hansson O, Zetterberg H, Buchhave P, Londos E, Blennow K, Minthon L. Association between CSF biomarkers and incipient Alzheimer's disease in patients with mild cognitive impairment: a follow-up study. [Erratum appears in Lancet Neurol 2006; 5 (4): 293]. Lancet Neurology 2006; 5 (3): 228-34.

41. Barber R, Ballard C, McKeith IG, Gholkar A, O'Brien JT. MRI volumetric study of dementia with Lewy bodies: a comparison with AD and vascular dementia. Neurology 2000; 54 (6): 1304-9.

42. Ballard C, Jones EL, Londos E, Minthon L, Francis P, Aarsland D. alpha-Synuclein antibodies recognize a protein present at lower levels in the CSF of patients with dementia with Lewy bodies. Int Psychogeriatr 2010; 22 (2): 321-7.

43. Aarsland D, Kurz M, Beyer M, Bronnick K, Piepenstock NS, Ballard C. Early discriminatory diagnosis of dementia with Lewy bodies. The emerging role of CSF and imaging biomarkers. Dement Geriatr Cogn Disord 2008; 25 (3): 195-205.

44. Kemp PM, Holmes C. Imaging in dementia with Lewy bodies: a review. Nucl Med Commun $2007 ; 28$ (7): 511-9.

45. Walker Z, Jaros E, Walker RW, Lee L, Costa DC, Livingston G, et al. Dementia with Lewy bodies: a comparison of clinical diagnosis, FP-CIT single photon emission computed tomography imaging and autopsy. $J$ Neurol Neurosurg Psychiatry 2007; 78 (11): 1176-81.

46. McKeith I, O'Brien J, Walker Z, Tatsch K, Booij J, Darcourt J, et al. Sensitivity and specificity of dopamine transporter imaging with 123I-FP-CIT SPECT in dementia with Lewy bodies: a phase III, multicentre study. Lancet Neurol 2007; 6 (4): 305-13.

47. O'Brien JT, McKeith IG, Walker Z, Tatsch K, Booij J, Darcourt J, et al. Diagnostic accuracy of 123I-FP-CIT SPECT in possible dementia with Lewy bodies. Br J Psychiatry 2009; 194 (1): 34-9.

48. Svenningsson P, Westman E, Ballard C, Aarsland D. Cognitive impairment in patients with Parkinson's disease: diagnosis, biomarkers and treatment. Lancet Neurol 2012; 11 (8): 695-707

49. Aarsland D, Zaccai J, Brayne C. A systematic review of prevalence studies of dementia in Parkinson's disease. Mov Disord 2005; 20 (10): 1255-63.

50. Riedel O, Klotsche J, Spottke A, Deuschl G, Forstl H, Henn F, et al. Frequency of dementia, depression, and other neuropsychiatric symptoms in 1,449 outpatients with Parkinson's disease. J Neurol 2010; 257 (7): 1073 82 .

51. Aarsland D, Andersen K, Larsen JP, Lolk A, Kragh-Sorensen P. Prevalence and characteristics of dementia in Parkinson disease: an 8-year prospective study. Arch Neurol 2003; 60 (3): 387-92.

52. Hely MA, Reid WG, Adena MA, Halliday GM, Morris JG. The Sydney multicenter study of Parkinson's disease: the inevitability of dementia at 20 years. Mov Disord 2008; 23 (6): 837-44.

53. Evans JR, Mason SL, Williams-Gray CH, Foltynie T, Brayne C, Robbins TW, et al. The natural history of treated Parkinson's disease in an incident, community based cohort. J Neurol Neurosurg Psychiatry $2011 ; \mathbf{8 2}$ (10): 1112-8.

54. Aarsland D, Kvaloy JT, Andersen K, Larsen JP, Tang MX, Lolk A, et al. The effect of age of onset of PD on risk of dementia. J Neurol 2007; 254 (1): 38-45.

55. Aarsland D, Andersen K, Larsen JP, Perry R, Wentzel-Larsen T, Lolk A, et al. The rate of cognitive decline in Parkinson disease. Arch Neurol 2004; 61 (12): 1906-11.

56. Aarsland D, Muniz G, Matthews F. Nonlinear decline of mini-mental state examination in Parkinson's disease. Mov Disord 2011; 26 (2): 334-7.

57. Johnson DK, Galvin JE. Longitudinal changes in cognition in Parkinson's disease with and without dementia. Dement Geriatr Cogn Disord 2011; 31 (2): 98-108.

58. Kempster PA, O'Sullivan SS, Holton JL, Revesz T, Lees AJ. Relationships between age and late progression of Parkinson's disease: a clinico-pathological study. Brain 2010; 133 (Pt 6): 6-62.

59. Halliday GM, McCann H. The progression of pathology in Parkinson's disease. Ann N Y Acad Sci 2010; 1184: 188-95.

60. Postuma RB, Gagnon JF, Vendette M, Fantini ML, Massicotte-Marquez J, Montplaisir J. Quantifying the risk of neurodegenerative disease in idiopathic REM sleep behavior disorder. Neurology 2009; 72 (15): 1296-300.

61. Baba T, kikuchi A, Hirayama K, Nishio Y, Hosokai Y, Kanno S, et al. Severe olfactory dysfunction is a prodromal symptom of dementia associated with Parkinson`s disease: a 3 year longitudinal study. Brain 2012; 135 (1): 161-9.

62. Kurz MW, Schlitter AM, Larsen JP, Ballard C, Aarsland D. Familial occurrence of dementia and parkinsonism: a systematic review. Dement Geriatr Cogn Disord 2006; 22 (4): 288-95.

63. Seto-Salvia N, Clarimon J, Pagonabarraga J, Pascual-Sedano B, Campolongo A, Combarros O, et al. Dementia risk in Parkinson disease: disentangling the role of MAPT haplotypes. Arch Neurol 2011; 68 (3): 359-64.

64. Goris A, Williams-Gray CH, Clark GR, Foltynie T, Lewis SJ, Brown J, et al. Tau and alpha-synuclein in susceptibility to, and dementia in, Parkinson's disease. Ann Neurol 2007; 62 (2): 145-53. 
65. Aarsland D, Perry R, Brown A, Larsen JP, Ballard C. Neuropathology of dementia in Parkinson's disease: a prospective, community-based study. Ann Neurol 2005; 58 (5): 773-6.

66. Neumann J, Bras J, Deas E, O'Sullivan SS, Parkkinen L, Lachmann RH, et al. Glucocerebrosidase mutations in clinical and pathologically proven Parkinson's disease. Brain 2009; 132 (Pt 7): 7-94.

67. Alcalay RN, Caccappolo E, Mejia-Santana H, Tang MX, Rosado L, Orbe RM, et al. Cognitive performance of GBA mutation carriers with early-onset PD: The CORE-PD study. Neurology 2012; 78 (18): 1434-40.

68. Alcalay RN, Mejia-Santana H, Tang MX, Rakitin B, Rosado L, Ross B, et al. Self-report of cognitive impairment and mini-mental state examination performance in PRKN, LRRK2, and GBA carriers with early onset Parkinson's disease. J Clin Exp Neuropsychol 2010; 32 (7): 775-9.

69. Williams-Gray CH, Evans JR, Goris A, Foltynie T, Ban M, Robbins TW, et al. The distinct cognitive syndromes of Parkinson's disease: 5 year follow-up of the CamPaIGN cohort. Brain 2009; 132 (Pt 11): 11-69.

70. Williams-Gray CH, Goris A, Saiki M, Foltynie T, Compston DA, Sawcer SJ, et al. Apolipoprotein E genotype as a risk factor for susceptibility to and dementia in Parkinson's disease. J Neurol 2009; 256 (3): 493-8.

71. Kurz MW, Dekomien G, Nilsen OB, Larsen JP, Aarsland D, Alves G. APOE alleles in Parkinson disease and their relationship to cognitive decline: a population-based, longitudinal study. J Geriatr Psychiatry Neurol 2009; 22 (3): 166-70.

72. Lane R, He Y, Morris C, Leverenz JB, Emre M, Ballard C. BuChE-K and APOE epsilon4 allele frequencies in Lewy body dementias, and influence of genotype and hyperhomocysteinemia on cognitive decline. Mov Disord 2009; 24 (3): 392-400.

73. Aarsland D, Bronnick K, Williams-Gray C, Weintraub D, Marder K, Kulisevsky J, et al. Mild cognitive impairment in Parkinson disease: a multicenter pooled analysis. Neurology 2010; 75 (12): 1062-9.

74. Aarsland D, Bronnick K, Larsen JP, Tysnes OB, Alves G, Norwegian ParkWest study group. Cognitive impairment in incident, untreated Parkinson disease: the Norwegian ParkWest study. Neurology 2009; 72 (13): 1121-6.

75. Litvan I, Goldman JG, Troster AL, Schmand BA, Weintraub D, Petersen RC, et al. Diagnostic criteria for mild cognitive impairment in Parkinson`s disease. Movement Disorder Society Task Force guidelines. Mov Disord 2012; 27 (3): 349-56.

76. Bronnick K, Alves G, Aarsland D, Tysnes OB, Larsen JP. Verbal memory in drug-naive, newly diagnosed Parkinson's disease. The retrieval deficit hypothesis revisited. Neuropsychology 2011; 25 (1): 114-24.

77. Klassen BT, Hentz JG, Shill HA, Driver-Dunckley E, Evidente VG, Sabbagh MN, et al. Quantitative EEG as a predictive biomarker for Parkinson disease dementia. Neurology 2011; 77 (2): 118-24.

78. Siderowf A, Xie SX, Hurtig H, Weintraub D, Duda J, Chen-Plotkin A, et al. CSF amyloid $\beta$ 1-42 predicts cognitive decline in Parkinson disease. Neurology 2010; 75 (12): 1055-61.

79. Chen-Plotkin AS, Hu WT, Siderowf A, Weintraub D, Goldmann GR, Hurtig HI, et al. Plasma epidermal growth factor levels predict cognitive decline in Parkinson disease. Ann Neurol 2011; 69 (4): 655-63.

80. Dujardin K, Defebvre L, Duhamel A, Lecouffe P, Rogelet P, Steinling M, et al. Cognitive and SPECT characteristics predict progression of Parkinson's disease in newly diagnosed patients. J Neurol 2004; 251 (11): 1383-92.

81. Bohnen NI, Koeppe RA, Minoshima S, Giordani B, Albin RL, Frey KA, et al. Cerebral glucose metabolic features of Parkinson disease and incident dementia: longitudinal study. J Nucl Med 2011; 52 (6): 848-55.

82. Burton EJ, McKeith IG, Burn DJ, Williams ED, O'Brien JT. Cerebral atrophy in Parkinson's disease with and without dementia: a comparison with Alzheimer's disease, dementia with Lewy bodies and controls. Brain 2004; 127 (Pt 4): 4-800.

83. Kenny ER, Burton EJ, O'Brien JT. A volumetric magnetic resonance imaging study of entorhinal cortex volume in dementia with lewy bodies. A comparison with Alzheimer's disease and Parkinson's disease with and without dementia. Dement Geriatr Cogn Disord 2008; 26 (3): 218-25.

84. Lyoo CH, Ryu YH, Lee MS. Topographical distribution of cerebral cortical thinning in patients with mild Parkinson's disease without dementia. Mov Disord 2010; 25 (4): 496-9.

85. Song SK, Lee JE, Park HJ, Sohn YH, Lee JD, Lee PH. The pattern of cortical atrophy in patients with Parkinson's disease according to cognitive status. Mov Disord 2011; 26 (2): 289-96.

86. Weintraub D, Doshi J, Koka D, Davatzikos C, Siderowf AD, Duda JE, et al. Neurodegeneration across stages of cognitive decline in Parkinson disease. Arch Neurol 2011; 68 (12): 1562-8.

87. Beyer MK, Janvin CC, Larsen JP, Aarsland D. A magnetic resonance imaging study of patients with Parkinson's disease with mild cognitive impairment and dementia using voxel-based morphometry. J Neurol Neurosurg Psychiatry 2007; 78 (3): 254-9.

88. Weintraub D, Dietz N, Duda JE, Wolk DA, Dosji J, et al. Alzheimer's disease pattern of brain atrophy predicts cognitive decline in Parkinson`s disease. Brain 2012; 135 (Pt 1): 170-80.

89. Huang C, Mattis P, Perrine K, Brown N, Dhawan V, Eidelberg D. Metabolic abnormalities associated with mild cognitive impairment in Parkinson disease. Neurology 2008; 70 (16 Pt 2): 1470-7. 
90. Jokinen P, Scheinin N, Aalto S, Någren K, Savisto N, Parkkola R, et al. $\left[{ }^{11} \mathrm{C}\right] \mathrm{PIB}-,\left[{ }^{18} \mathrm{~F}\right] \mathrm{FDG}-\mathrm{PET}$ and MRI imaging in patients with Parkinson's disease with and without dementia. Parkinsonism Relat Disord $2010 ; 16$ (10): 666-70.

91. Firbank MJ, Colloby SJ, Burn DJ, McKeith IG, O'Brien JT. Regional cerebral blood flow in Parkinson's disease with and without dementia. Neuroimage 2003; 20 (2): 1309-19.

92. Nobili F, Abbruzzese G, Morbelli S, Marchese R, Girtler N, Dessi B, et al. Amnestic mild cognitive impairment in Parkinson's disease: a brain perfusion SPECT study. Mov Disord 2009; 24 (3): 414-21.

93. Montine TJ, Shi M, Quinn JF, Peskind ER, Craft S, Ginghina C, et al. CSF A $\beta_{42}$ and tau in Parkinson's disease with cognitive impairment. Mov Disord 2010; 25 (15): 2682-5.

94. Alves G, Bronnick K, Aarsland D, Blennow K, Zetterberg H, Ballard C, et al. CSF amyloid-beta and tau proteins, and cognitive performance, in early and untreated Parkinson's disease: the Norwegian ParkWest study. $J$ Neurol Neurosurg Psychiatry 2010; 81 (10): 1080-6.

95. Mollenhauer B, Locascio JJ, Schulz-Schaeffer W, Sixel-Doring F, Trenkwalder C, Schlossmacher MG. alphaSynuclein and tau concentrations in cerebrospinal fluid of patients presenting with parkinsonism: a cohort study [Erratum appears in Lancet Neurol 2011; 10 (4): 297]. Lancet Neurol 2011; 10 (3): 230-40.

96. Tokuda T, Qureshi MM, Ardah MT, Varghese S, Shehab SA, Kasai T, et al. Detection of elevated levels of alpha-synuclein oligomers in CSF from patients with Parkinson disease. Neurology 2010; 75 (20): 1766-72.

97. Bostrom F, Jonsson L, Minthon L, Londos E. Patients with Lewy body dementia use more resources than those with Alzheimer's disease. Int J Geriatr Psychiatry 2007; 22 (8): 713-9.

98. Bostrom F, Jonsson L, Minthon L, Londos E. Patients with dementia with lewy bodies have more impaired quality of life than patients with Alzheimer disease. Alzheimer Dis Assoc Disord 2007; 21 (2): 150-4.

99. Vossius C, Larsen JP, Janvin C, Aarsland D. The economic impact of cognitive impairment in Parkinson's disease. Mov Disord 2011; 26 (8): 1541-4. 